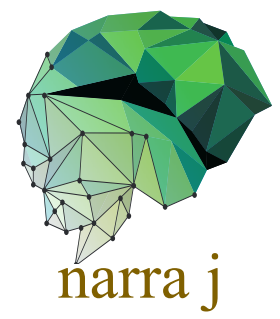

Short Communication

\title{
Correlation of neutrophil-to-lymphocyte ratio and clinical outcome of acute thrombotic stroke in patients with COVID-19
}

\author{
Rizky F. Sarengat ${ }^{1,2^{*}}$, Mohammad S. Islam ${ }^{1,2}$ and Mohammad S. Ardhi, \\ 'Department of Neurology, Faculty of Medicine, Universitas Airlangga, Surabaya, Indonesia; 'Department of Neurology, \\ Dr. Soetomo General Hospital Surabaya, Indonesia \\ *rizkyfawzyana@gmail.com
}

\begin{abstract}
The coronavirus disease 2019 (COVID-19) pandemic has caused millions of deaths worldwide. Acute ischemic stroke is a life-threatening risk factor for COVID-19 infection. Neutrophil-to-lymphocyte ratio (NLR) is one of the predictors of poor prognosis in acute ischemic stroke. The aim of this study was to assess the correlation between NLR values and the clinical outcome of acute thrombotic stroke patients with COVID-19 that was measured using the National Institutes of Health Stroke Scale (NIHSS). A crosssectional hospital-based study was conducted in Dr. Soetomo General Hospital Surabaya, Indonesia. Patients with acute thrombotic stroke and COVID-19 admitted between 1 March 2020 and 31 May 2021 were recruited. The NLR values and the NIHSS scores were assessed during the admission and the correlation between NLR and NIHSS scores was calculated. This study included 21 patients with acute thrombotic stroke and COVID-19, consisting of 12 males and 9 females. The mean age was 57.6 years old. The mean NLR values was $8.33 \pm 6.7$ and the NIHSS scores ranging from 1 to 33 . Our data suggested a positive correlation between NLR values and NIHSS scores, $r=0.45$ with $\mathrm{p}=0.041$. In conclusion, the NLR value is potentially to be used as a predictor of the clinical outcome in acute thrombotic stroke patients with COVID-19. However, further study is warranted to validate this finding.
\end{abstract}

Keywords: Acute thrombotic stroke, COVID-19, neutrophil-to-lymphocyte ratio, NLR, predictor

\section{Introduction}

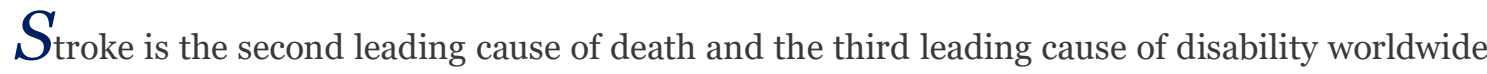
[1]. Stroke survivors are often burdened with rehabilitation costs, lost income and productivity, limitations in daily social activities, and significant residual disabilities [2]. Coronavirus disease 2019 (COVID-19) pandemic, caused by severe acute respiratory syndrome coronavirus 2 (SARSCoV-2), has caused more than 4.9 million deaths worldwide as of October 24, 2021 [3]. Acute cerebrovascular events are one of the neurological complications of COVID-19 [4]. Acute ischemic stroke is one of the non-traditional, life-threatening risk factors for COVID-19 infection. The incidence of acute ischemic stroke in COVID-19 patients ranges between 0.92.7\% [5]. Acute ischemic stroke with COVID-19 has a poorer outcome and higher mortality than non-COVID-19 ischemic stroke [6]. The etiology of ischemic stroke is due to thrombotic or embolic events. In thrombotic etiology, blood flow to the brain is obstructed due to dysfunction 
within the vessels, which may be secondary to atherosclerotic disease or inflammatory conditions [7].

The neutrophil-to-lymphocyte ratio (NLR) represents a balance between the levels of neutrophils and lymphocytes in the body, as well as an indicator of systemic inflammation. NLR is an independent predictor of mortality in various diseases [8]. From previous studies, patients with severe COVID-19 showed higher NLR on admission [8,9]. NLR $>4$ is considered as a predictor for admission of COVID-19 patients to ICU [10]. Higher NLR values serve as an independent predictor of poorer prognosis in patients with acute ischemic stroke, heart disease, and cancer [11]. Prediction of outcome in acute stroke patients has important clinical practices. It can be clinically used to guide patient management (i.e., patients with a good prognosis could avoid high-risk treatments such as thrombolysis), improve rehabilitation and discharge plans, and provide more reliable information to patients and their families [12].

This study was conducted to determine the correlation between NLR values and clinical outcomes of acute thrombotic stroke patients with COVID-19. Clinical outcomes of acute thrombotic stroke were assessed using a simple and rapid score for stroke in emergency evaluation, the National Institutes of Health Stroke Scale (NIHSS) [13].

\section{Methods}

A cross-sectional hospital-based study was conducted in Dr. Soetomo General Hospital Surabaya, Indonesia. The clinical data were obtained from medical records of acute thrombotic stroke patients with COVID-19 that were hospitalized in the Isolation and Emergency ward between 1 March 2020 and 31 May 2021. Acute thrombotic stroke patients with COVID-19 who met the inclusion were considered eligible. The inclusion criteria comprised patients who: (a) had the first attack of acute thrombotic stroke; (b) had laboratory examinations and head computerized tomography scan (CT-scan) without contrast; (c) experienced stroke onset less than 72 hours; and (d) have been diagnosed with COVID-19 infection.

Diagnosis confirmation of COVID-19 was performed based on clinical manifestations and real-time reverse transcription-polymerase chain reaction (RT-PCR) of the nasopharyngeal swab. All acute thrombotic stroke patients with a history of malignancy, head trauma, or other sources of infection other than COVID-19 were excluded. NLR was measured from complete blood tests during the first admission to the hospital. The clinical outcome of acute thrombotic stroke, measured at admission time, was assessed using the NIHSS scale. NIHSS was assessed on eleven items measuring the level of dysfunction including the domains of language, ataxia, motor strength, sensation, and neglect. The score is an ordinal scale (range o to 42) [13,14]. Demographic and clinical data were also collected.

The Shapiro-Wilk was used to assess the normality of the data and Spearman rank correlation statistical test was employed to assess the correlation between NLR and NIHSS scores. A p-value lower than 0.05 was considered statistically significant. All analyses were conducted using SPSS 22 software. This study was approved by the Health Research Ethics Committee of RSUD Dr. Soetomo (No. 0400/LOE/301.4.2/III/2021).

\section{Results}

Thirty patients diagnosed with acute thrombotic stroke and COVID-19 were recruited. Out of the total patients, 21 were considered eligible to be included in the final analysis (Figure 1). The number of male and female patients included in this research was 12 (57.1\%) and 9 (42.8\%),

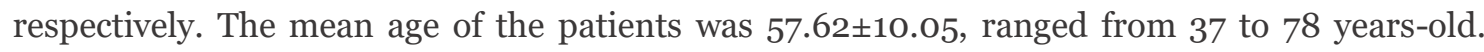
None of the patients received thrombolytic therapy. The basic demographic and clinical characteristics of the patients are provided in Table $\mathbf{1 .}$

Our analysis found that the NLR data in this study were not normally distributed. The minimum NLR value was 0.71 and the maximum was 23.3. The median and average of NLR were $6.74 \pm 11.67$ and $8.33 \pm 6.69$, respectively (Table 1). The NIHSS data, however, normality distributed with the minimum and the maximum values of the NIHSS scale 1 and 33, respectively (Table 1). The correlation analysis using the Spearman rank correlation test 
suggested a positive moderate strength correlation between NLR values and NIHSS scores, $\mathrm{r}=0.45$ with $\mathrm{p}=0.041$.

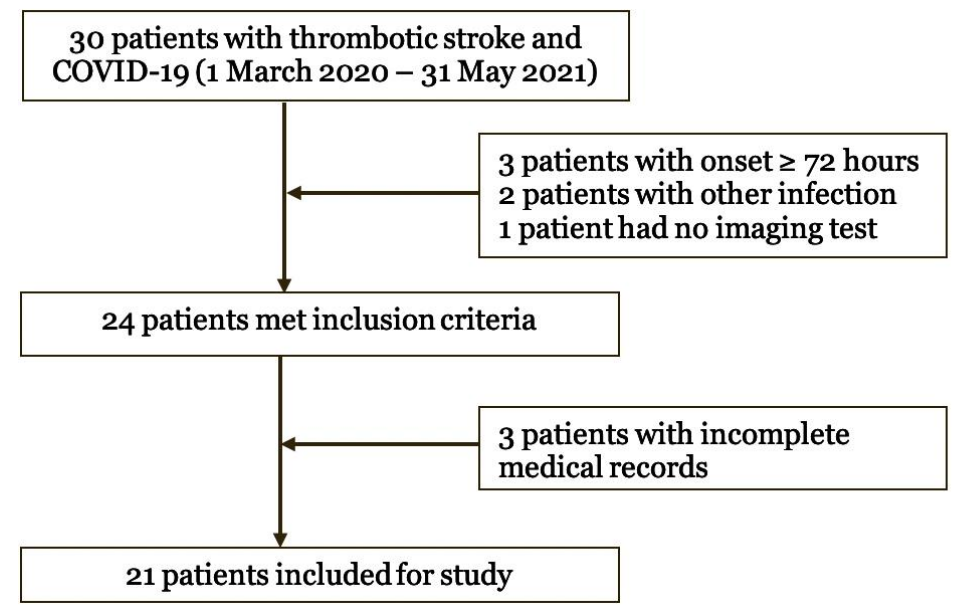

Figure 1. Flow diagram of study selection

Table 1. The characteristic of patients with thrombotic stroke and COVID-19 ( $\mathrm{n}=21)$

\begin{tabular}{|c|c|c|}
\hline Variable & Mean \pm SD & Min-max \\
\hline \multicolumn{3}{|l|}{ Sex, n (\%) } \\
\hline Male & $12(57.1)$ & \\
\hline Female & $9(42.8)$ & \\
\hline Age (years) & $57.62 \pm 10.0$ & $37-78$ \\
\hline Systolic blood pressure & $143 \pm 25.4$ & $96-190$ \\
\hline Diastolic blood pressure & $85 \pm 14.9$ & $65-123$ \\
\hline \multicolumn{3}{|l|}{ Comorbidities } \\
\hline Hypertension, $\mathrm{n}(\%)$ & $16(76.1)$ & \\
\hline Diabetes mellitus, $\mathrm{n}(\%)$ & $14(66.6)$ & \\
\hline \multicolumn{3}{|l|}{ Laboratory parameters } \\
\hline Dyslipidemia, n (\%) & $9(42.8)$ & \\
\hline Blood glucose (mg/dL) & $208.09 \pm 98.2$ & $90-408$ \\
\hline Hemoglobin (g/dL) & $13.23 \pm 1.4$ & $11.2-16.1$ \\
\hline C-reactive protein $(\mathrm{mg} / \mathrm{dL})$ & $5 \cdot 41 \pm 5 \cdot 7$ & $0.1-17.6$ \\
\hline Leukocyte $(/ \mu \mathrm{L})$ & $10,472.86 \pm 2,856.7$ & $4,470-17,100$ \\
\hline Neutrophil-to-lymphocyte ratio (NLR) & $8.33 \pm 6.7$ & $0.71-23.3$ \\
\hline NIHSS score & $12.76 \pm 9.3$ & $1-33$ \\
\hline
\end{tabular}

\section{Discussion}

In total, 21 patients who met the inclusion criteria were included in this study in which the proportion of male participants was more frequent (57.1\%). This finding confirms that of a previous study revealing that male has a higher risk of stroke compared to female, and gender is one of the unmodifiable risk factors for stroke [14]. The mean age of the patients was 57.6 years old. This is because the stroke has traditionally been considered a disease of the elderly with incidence rates doubling for each decade after the age of 55 years [15].

Higher NLR is due to an increase in the number of neutrophils and a decrease in the number of lymphocytes [8]. NLR is advantageous since it is simple to test, requires low cost, and is easily available when compared to other biomarkers [16]. Data suggest that NLR is a very useful and significant indicator in bacterial pneumonia and viral infections [17]. We found the mean NLR value (8.33) in acute thrombotic stroke patients with COVID-19 was higher compared to that in ischemic stroke patients without COVID-19 (mean value of 5.12) as reported in the previous study by Ummah et. al. [18]. 
Several mechanisms explain why the NLR value in acute ischemic stroke patients with COVID-19 infection is high than that in acute ischemic stroke without COVID-19 infection. Neutrophils in ischemic stroke peaked 24-72 hours after the stroke onset and decreased rapidly over time [19]. Low lymphocyte counts are caused by systemic stress after stroke, which promotes the activation of the renin-angiotensin system, resulting in cortisol release and lymphocyte apoptosis [20]. Analysis of lung autopsy samples from COVID-19 patients showed neutrophil infiltration in the pulmonary capillaries, extravasation of neutrophils into the alveolar space, and neutrophilic mucositis [17]. A prominent feature of COVID-19 is multiorgan inflammation with vessel walls containing neutrophils [17]. Systemic viral infection is usually accompanied by lymphocytosis [8]; however, in SARS-CoV-2 infection, the virus could attack lymphocytes, particularly T lymphocytes [17]. The mechanism of COVID-19 associated with the reduced number of T-cells is apoptosis since SARS-CoV-2 could induce lymphocyte apoptosis [21].

The correlation between the NLR value and the NIHSS scale was positive and moderate $(\mathrm{r}=0.45 ; \mathrm{p}=0.041)$; hence the higher the NLR value, the greater the NIHSS scale. This is in line with previous investigations suggesting that neutrophils were involved and had an important role in brain injury by exacerbating oxidative stress, blood-brain barrier damage, and risk of reinfarction [19,22]. Blood-brain barrier damage is also associated with an increased risk of hemorrhagic transformation in acute ischemic stroke [19]. On the other hand, lymphocytes have a neuroprotective effect [20]. A previous study has also estimated that the high NLR value at admission was associated with greater complications associated with COVID-19 infection [23].

There are some limitations regarding the current investigation that should be discussed. The study was conducted in a single healthcare center leading to a small sample size that could be included in the final analysis; therefore, further studies carried out in multiple healthcare centers are important to be conducted in Indonesia. Moreover, some confounding variables that might contribute to NIHSS scales were not controlled in this study. We did not classify the COVID-19 based on the severity, which could be the source of bias in the analysis.

\section{Conclusions}

There was a positive and moderate correlation between NLR values and clinical outcome of acute ischemic stroke patients with COVID-19. However, further studies are necessary, in particular, to analyze the confounding variables affecting NIHSS and NLR values.

\section{Ethics approval}

Not required.

\section{Acknowledgments}

The authors would like to thank Dr. Soetomo General Hospital Surabaya, Indonesia for the support.

\section{Conflict of interest}

The authors declare that they have no competing interests.

\section{Funding}

This study did not receive any specific grant from funding agencies in the public, commercial, or not-for-profit sectors.

\section{Underlying data}

All data underlying the results are available as part of the article. 


\section{How to cite}

Sarengat RF, Islam MS, Ardhi MS. Correlation of neutrophil-to-lymphocyte ratio and clinical outcome of acute thrombotic stroke in patients with COVID-19. Narra J 2021; 1(3): e50. http://doi.org/10.52225/narra.v1i3.50.

\section{References}

1. Johnson W, Onuma O, Owolabi M, Sachdev S. Stroke: A global response is needed. Bull World Health Organ 2016:94(9):634A-635A.

2. Papanagiotou $\mathrm{P}$, White CJ. Endovascular reperfusion strategies for acute stroke. JACC Cardiovasc Interv 2016;9(4):307-317.

3. World Health Organization. WHO Coronavirus (COVID-19) Dashboard. Available from: https://covid19.who.int/ (Accessed: 24 October 2021).

4. Wiersinga WJ, Rhodes A, Cheng AC, et al. Pathophysiology, Transmission, Diagnosis, and Treatment of Coronavirus Disease 2019 (COVID-19): A Review. JAMA 2020;2019:1-13.

5. Tan YK, Goh C, Leow AST, et al. COVID-19 and ischemic stroke: a systematic review and meta-summary of the literature. J Thromb Thrombolysis 2020; 50(3):587-595.

6. Ntaios G, Michel P, Georgiopoulos G, et al. Characteristics and outcomes in patients with COVID-19 and acute ischemic stroke: The Global COVID-19 Stroke Registry. Stroke 2020;51(9):e254-e258.

7. Hui C, Tadi P, Patti L. Ischemic Stroke - StatPearls - NCBI Bookshelf [Internet]. StatPearls Publishing. 2020. Available from: https://www.ncbi.nlm.nih.gov/books/NBK499997/ (Accessed: 1 October 2021).

8. Wang $\mathrm{Y}, \mathrm{Ju} \mathrm{M}$, Chen $\mathrm{C}$, et al. Neutrophil-to-lymphocyte ratio as a prognostic marker in acute respiratory distress syndrome patients: A retrospective study. J Thorac Dis. 2018;10(1):273-282.

9. Qin C, Zhou L, Hu Z, et al. Dysregulation of immune response in patients with COVID-19 in Wuhan, China. Clin Infect Dis. 2020;71(15):762-768.

10. Ciccullo A, Borghetti A, Zileri Dal Verme L, et al. Neutrophil-to-lymphocyte ratio and clinical outcome in COVID-19: a report from the Italian front line. Int J Antimicrob Agents 2020;56(2):106017.

11. Qun S, Tang Y, Sun J, et al. Neutrophil-to-lymphocyte ratio predicts 3-month outcome of acute ischemic stroke. Neurotox Res 2017;31(3):444-452.

12. Counsell C, Dennis M. Systematic review of prognostic models in patients with acute stroke. Cerebrovasc Dis 2001;12(3):159-170.

13. Powers WJ, Rabinstein AA, Ackerson T, et al. 2018 Guidelines for the Early Management of Patients With Acute Ischemic Stroke: A Guideline for Healthcare Professionals From the American Heart Association/American Stroke Association. Stroke 2018; 49:46-110

14. Caplan LR. Caplans Stroke, A Clinical Approach. 5th ed. Vol. 148. Cambridge University Press; 2016: 148-162

15. Soto-Cámara R, González-Bernal JJ, González-Santos J, et al. Age-related risk factors at the first stroke event. J Clin Med 2020;9(7):2233.

16. Hwang SY, Shin TG, Jo IJ, et al. Neutrophil-to-lymphocyte ratio as a prognostic marker in critically-ill septic patients. Am J Emerg Med 2017;35(2):234-239.

17. Nalbant A, Kaya T, Varim C, et al. Can the neutrophil/lymphocyte ratio (NLR) have a role in the diagnosis of coronavirus 2019 disease (COVID-19)? Rev Assoc Med Bras 2020;66(6):746-51.

18. Ummah F, Belladonna M, Retnaningsih R. Rasio neutrofil limfosit darah tepi sebagai indikator outcome pada stroke iskemik akut. Diponegoro Med J 2016;5(4):827-841.

19. Song SY, Zhao XX, Rajah G, et al. Clinical significance of baseline neutrophil-to-lymphocyte ratio in patients with ischemic stroke or hemorrhagic stroke: an updated meta-analysis. Front Neurol 2019; 10:1032.

20. Ren H, Liu X, Wang L, Gao Y. Lymphocyte-to-monocyte ratio: a novel predictor of the prognosis of acute ischemic stroke. J Stroke Cerebrovasc Dis 2017;26(11):2595-2602.

21. Schönrich G, Raftery MJ, Samstag Y. Devilishly radical NETwork in COVID-19: Oxidative stress, neutrophil extracellular traps (NETs), and T cell suppression. Adv Biol Regul. 2020;77: 100741.

22. Tokgoz S, Kayrak M, Akpinar Z, et al. Neutrophil lymphocyte ratio as a predictor of stroke. J Stroke Cerebrovasc Dis. 2013;22(7):1169-1174.

23. Yan X, Li F, Wang $X$, et al. Neutrophil to lymphocyte ratio as prognostic and predictive factor in patients with coronavirus disease 2019: A retrospective cross-sectional study. J Med Virol 2020;92(11):2573-2581. 